\title{
Police referrals - a crisis intervention approach
}

\author{
JANice Morgan, Registrar in Psychiatry, Psychiatric Unit, Barnet General Hospital; and \\ JoHN CoRdIngly, Consultant Psychiatrist, Napsbury Hospital, London Colney, \\ Nr St Albans, Herts AL2 1AA
}

Recently, concern has been expressed by mental health professionals, MIND, and the police regarding the management of Section 136 referrals, which at present varies according to the local psychiatric services available. In the majority of London Metropolitan Boroughs a person deemed to be in need of care and control is taken first to a police station where the necessary documentation is completed and then transported, often a considerable distance, to a mental hospital for the purpose of assessment. This can result in lengthy delays in a police cell for the patient, time-consuming negotiations with hospitals for the police, and problems completing the assessment procedure due to lack of availability of social workers. The importance of considering alternatives, particularly with the move towards community care, has been stressed.

In addition to the practical problems of the current assessment procedures, it has been suggested that the location of the assessment has a greater effect on outcome than the clinical or social presentation of referred patients by the police (Rassaby \& Rogers, 1987), and the recent Code of Practice recommends that "regard should be had to any impact different types of place of safety may have on the person held and hence on the outcome of an assessment".

\section{The study}

A community crisis intervention service (CCIS) operates at Barnet and Napsbury Hospitals providing a 24-hour comprehensive service to the London Borough of Barnet and parts of Hertfordshire, a catchment area population of 350,000. The team consists of a psychiatrist, a social worker, and a community psychiatric nurse; it provides a multidisciplinary assessment for all emergency referrals including police referrals, such assessments taking place in catchment area police stations which are designated as 'places of safety'. All police referrals to the service during a six month period were entered in the study as it was frequently difficult to determine the legal status of the patient, which has been the finding of other studies (Weller et al, 1988; Rassaby \& Rogers, 1987).

Following each police referral, one of the researchers interviewed the members of the crisis team to determine the reason for police involvement, age, sex, ethnic origin, and type and place of residence of referred patients, as well as previous psychiatric history. The psychiatrists on the teams were requested to assign each patient to an ICD-9 diagnostic category and the outcome of the assessment in terms of patient 'disposal' was documented. A questionnaire on the police opinion of the service was concurrently sent to the custody officer of the police station.

One month after their referral, all patients residing within the catchment area were followed up to determine outcome in terms of up-take of psychiatric services and re-referral rate from the police. This information was obtained from computer records and case-notes. Patient opinion of the service was sought at this stage using an anonymous questionnaire.

Recently published data from two different London based services, one an emergency assessment unit (EAU) and one a 'traditional' service accepting Section 136 admissions was used for comparison of outcome (Rassaby \& Rogers, 1987).

\section{Findings}

During the six months, a total of 82 subjects (49 males and 33 females) were referred by the police to the CCIS; ten of the patients were referred on more than one occasion giving a total of 93 referrals. The mean age of male referrals was 34.9 years and the mean age of females was 36.4 years. This compared with 667 referrals made to the CCIS by other agencies, mostly GPs, for urgent assessment during the same six month period. The police referrals to the service contained a significantly higher proportion of males, and both males and females were significantly younger when compared with the referrals made by other agencies. Of the sample, $76 \%$ were of Caucasian origin and $24 \%$ of Afro-Caribbean or Asian origin, compared with $87 \%$ Caucasian and $13 \%$ Afro-Caribbean or Asian living in the Borough (1981 census). This difference was significant $\left(\chi^{2}=\right.$ $12.7, P>0.0005$ with 1 degree of freedom). Of the subjects, $53.6 \%$ lived with family and friends, $30 \%$ lived alone or in multi-occupied accommodation and $13 \%$ were of no fixed abode. Of all female subjects, 
TABLE 1

Comparison of outcome of assessment by community crisis intervention service with two other services; one an emergency assessment unit and the other a traditional service

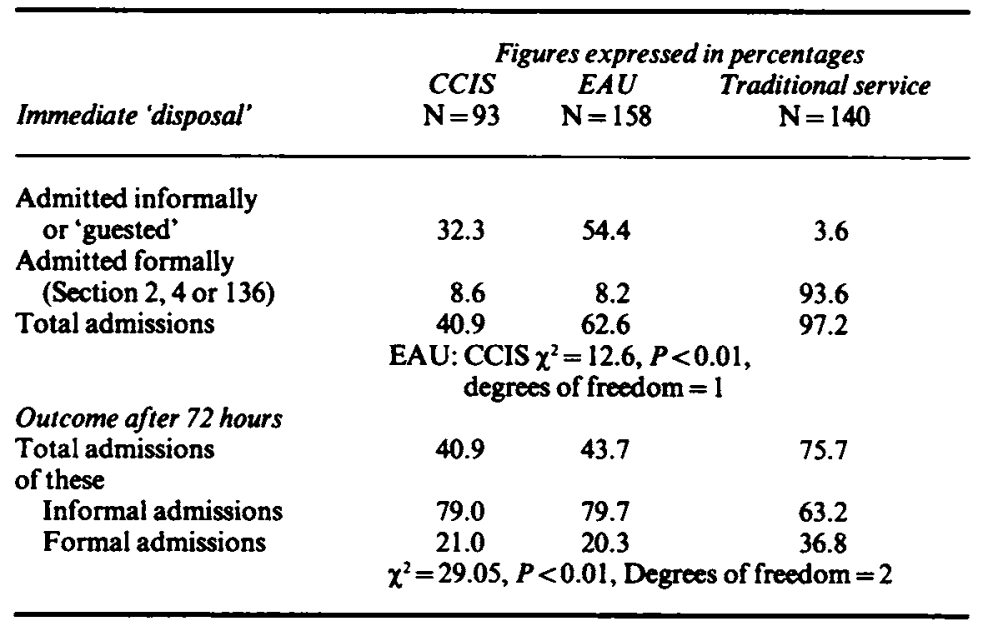

Figures for comparison taken from work done by Rassaby \& Rogers (1987) and Rogers \& Faulkner (1987).

$66.7 \%$ as opposed to $44.9 \%$ of male subjects, lived with family or friends, a significant difference $\left(X^{2}=4.684, P>0.05\right.$ with 1 degree of freedom).

There was a past psychiatric history (defined as in- or out-patient treatment) present in $87.8 \%$ of patients, with no significant difference between males and females. The ICD diagnosis most frequently assigned by the psychiatrists on the team was schizophrenia $32.9 \%$, with affective psychosis $20.9 \%$ and personality disorder $18.3 \%$. Only $8.5 \%$ of patients were not assigned to a diagnostic category.

The types of behaviour communicated by patients which brought them to the attention of the police are similar to those found by Sims \& Symonds (1975). The reasons for police involvement were 'wandering' $30.1 \%$, incidents involving violence or threat of violence $29 \%$, and public order offences $28 \%$. Assault or threat of assault was found to be equally common in male and female subjects.

Of the 93 referrals, $38(40.9 \%)$ were admitted to hospital, $24(25.8 \%)$ informally to Barnet or Napsbury, 6(6.5\%) informally to the catchment area of origin; $6(6.5 \%)$ were admitted on Section 2 , and 2 $(2.2 \%)$ were admitted on Section 136.

The team recommended that 11 of the referrals should be dealt with by the legal system although three of these were also offered psychiatric follow-up. A further 33 referrals were offered psychiatric followup including out-patient appointments $(16.1 \%)$, crisis management $(4.3 \%), \mathrm{CPN}(4.3 \%)$, and SW $(5.4 \%)$ visits, and hostel placement $(2.2 \%)$. Only 11
$(11.8 \%)$ were judged not to need further psychiatric intervention at that time; $4.3 \%$ refused all help.

These results were compared with the findings of the MIND researchers (Rassaby \& Rogers, 1987) who looked at two other types of service in London. One offered assessment of police referrals at an emergency assessment unit (EAU) and had a facility for 'guesting' patients for short-term crisis management. The other was a traditional service accepting referrals direct to the catchment area mental hospital and admitting patients under Section 136.

Comparing the overall admission rates, the CCIS was found to admit significantly fewer police referrals $(40.9 \%)$ than the EAU $(62.6 \%)$ and the traditional service $(97.2 \%)$. The comparison of formal admissions was CCIS (8.6\%) and EAU (8.2\%) whereas to the traditional service it was a much higher percentage $(93.6 \%$ ) (see Table 1 ).

The outcome after 72 hours showed no significant difference in formal or informal admissions between the CCIS and EAU. In the CCIS all the patients admitted were still in hospital after 72 hours $(40.9 \%)$. Of these, $21 \%$ were compulsorily detained, and similarly in the EAU the proportion compulsorily detained rose to $10.3 \%$.

There was a significantly higher percentage of the traditional service referrals who were still in-patients after 72 hours $(75.7 \%)$ and of these $36.8 \%$ were detained.

One month follow-up of the CCIS revealed that five of the patients not admitted at the initial assess- 
ment were subsequently admitted. Three of these patients were attending follow-up and were admitted voluntarily. One patient was admitted compulsorily from a crisis visit at the request of the GP and one was admitted following a further assessment at the police station. Of the 28 referrals offered follow-up, 17 were still being seen, five defaulted from treatment and there had been no further contact with the service. Three had been re-referred to the service and three had been admitted (as mentioned above).

Only 26 questionnaires were returned by the police. These revealed that the police were in agreement with the CCIS decision regarding management in $73 \%$ of the cases and were satisfied with the support given by the team in $61.5 \%$ of cases. The time taken for the crisis team to attend was less than two hours in $53.9 \%$ and less than four hours in $73 \%$ of calls.

The subjects' opinion about the service was difficult to evaluate as only 14 questionnaires were returned. Comments on the outcome of the assessment by the crisis team varied but the majority found the help and advice offered to be useful. The most common criticism was of being assessed in a police station and the distress this caused.

\section{Comment}

The socio-demographic and clinical characteristics of police referrals to the CCIS were similar to those found in earlier studies on Section 136 referrals in the context of the 1959 Act, both in London and in other large cities (Sims \& Symonds, 1975; Kelleher \& Copeland, 1972). Overall, subjects in our sample tended to be younger than other psychiatric referrals, with a high proportion of males living alone, or in multi-occupied accommodation. The percentage of referrals of no fixed abode was $13.4 \%$ which is comparable with other studies (Rassaby \& Rogers, 1987). Ethnic minorities were found to be over-represented.

During the study period, a total of 93 assessments were made. Each assessment was made jointly by a psychiatrist, an approved social worker and a community psychiatric nurse, functioning as a multidisciplinary team. A joint assessment is recommended by the Mental Health Commission and MIND, and obviates many of the problems experienced by the police in terms of negotiating beds, catchment area disputes and delays or absence of an approved social worker (Dunn \& Fahy, 1987). It also meant that compulsory admissions were made more appropriately under Part II of the Mental Health Act.

One month follow-up of our subjects suggested a substantial default rate: four patients did not attend follow-up after discharge from hospital and 11 patients did not take up the offer of follow-up after discharge from the police station.
The hypothesis put forward by Rassaby \& Rogers (1987) that the 'place of safety' affected the outcome of the assessment more than clinical or social considerations is supported by our findings. However, our research shows that the CCIS was able to offer alternatives to hospital care, such as active support and follow-up in the community by members of the crisis team, which might not be so readily available to other services.

An alternative explanation for the lower CCIS admission rates would be that patients requiring admission were being inappropriately released from the police station. This hypothesis is difficult to evaluate as there is little comparative data on followup of Section 136 patients. The re-referral rate of our Section 136 patients was no higher than other researchers (Kelleher \& Copeland, 1972; Sims \& Symonds, 1975; Rassaby \& Rogers, 1987). The considerable number of patients discharged after 72 hours by both the EAU and the traditional service would suggest that some of these patients had been admitted inappropriately.

It is not clear why patients who have frequently had many previous contacts with the psychiatric service enter treatment through police referral. Kelleher $\&$ Copeland (1972) suggested that the qualities of the personality and not any particular diagnostic category predisposed these patients to lapse from treatment and to present again by way of the police when under stress. It would appear from our study that the patients do tend to be mentally disordered but also to be socially disadvantaged.

For a Section 136 to be implemented, an individual communicates his or her disorder by behaving in such a manner that members of the public are made aware of it and they in turn bring this to the attention of the police. Such behaviour usually deviates from what is acceptable in the community but does not generally constitute an offence. With the closure of the large hospitals, it has been postulated that there will be an increase in Section 136 referrals. Alternatively, the community may become more tolerant of socially deviant behaviour. The results of studies to date have been conflicting (Weller et al, 1988).

Concern has been expressed regarding the involvement of the police in issues of mental health. The police are the only laymen who can pass judgement on an individual's mental state and need for compulsory detention. Police receive little or no formal training in mental health and apply the test of the common man'. Despite this lack of formal training, our study found considerable agreement between the police officers and psychiatric professionals as regards the presence of psychiatric morbidity. Only eight of the referrals were not assigned to a diagnostic category (two of these patients were later given a diagnosis). There was less agreement, however, about the need for compulsory detention as only 
eight of the 93 referrals were admitted compulsorily following assessment. Edeh (1987) made the point that patients detained on a Section 136 have no rights of complaint and have less rights than persons arrested on criminal charges.

The appropriateness of detaining a mentally disordered person in a cell for assessment is questionable. One important finding was that the use of the police station as the "place of safety" was generally considered unacceptable and we recommend that alternatives should be looked at.

The length of time taken by the CCIS to arrive was less than four hours on $73 \%$ of occasions. This is indeed a considerable time for a person awaiting assessment to remain in a cell. However, at present in the London Metropolitan Area, patients are first transported to a police station and have to wait on average three hours in a cell before being transferred to a hospital. Police opinion on the CCIS in terms of assessment made and support received, was difficult to evaluate due to a low response rate to the questionnaire.

As with other researchers, we experienced difficulties in following up this particular patient group and there was a very low response rate to the questionnaire. On balance the patients found the visit by the crisis team to be both acceptable and helpful.

In conclusion, the findings of this study would suggest that an assessment of Section 136 referrals by a multidisciplinary crisis intervention team using the area police station as the "place of safety" results in a lower overall admission rate with most formal admissions taking place under Part II of the Mental
Health Act. It is not clear which components of the service were responsible for these effects and whether the crisis model, the presence of a multidisciplinary team or the location of the assessment had greatest influence. This particular approach does, however, appear to be an effective and appropriate response to Section 136 referrals but does not address the broader issue of how to reduce the numbers of patients presenting to the psychiatric services in this manner.

\section{References}

DUNN, J. \& FAHY, T. (1987) Section 136 and the police. Bulletin of the Royal College of Psychiatrists, 11, 224-225.

EDEH, J. (1987) Patients' rights and the Mental Health Act. Lancet, $i, 45$.

Kelleher, M. J. \& Copeland, J. R. M. (1972) Compulsory psychiatric admissions by the police: a study in the use of Section 136. Medicine. Science and the Law, 12, 220-224.

RAsSABY, E. \& RoGERs, A. (1987) Psychiatric referrals from the police. Variations in disposal at different places of safety. Bulletin of the Royal College of Psychiatrists, 11, 78-81.

Rogers, A. \& Faulkner, A. (1987) A Place of Safety. London: MIND Publications.

Sims, A. C. P. \& Symonds, R. L. (1975) Psychiatric referrals from the police. British Journal of Psychiatry, 127, 171-178.

Weller, M. P. I., Weller, B. G. A., BaumanN, S. \& Coker, E. (1988) The local use of Section 136. Bulletin of the Royal College of Psychiatrists, 12, 235-236.

A full list of references is available from the authors on request. 